\title{
When will a Darwinian approach be useful for the study of society?
}

\author{
Samuel Bagg
}

NB: this is the "author-approved" version (AAV) of the manuscript

(i.e., the final draft after peer review and before publisher edits)

Journal: Politics, Philosophy and Economics: 16 (3)

Accepted: 13 October 2016

Published on Sage EarlyView: 10 January 2017 (link; doi: 10.1177/1470594X16687839)

AAV available on academia.edu: 10 January 2017 (link)

AAV available on ssrn.com: 15 January 2017 (link)

\begin{abstract}
In recent years, some have claimed that a Darwinian perspective will revolutionize the study of human society and culture. This project is viewed with disdain and suspicion, on the other hand, by many practicing social scientists. This paper seeks to clears the air in this heated debate by dissociating two claims which are too often assumed to be inseparable. The first is the "ontological" claim that Darwinian principles apply, at some level of abstraction, to human society and culture. The second is the more "pragmatic" claim that this observation necessitates substantial changes in the practices of social scientists. Even if some version of the first claim is true, I arguewhich I believe is quite likely - the second does not follow. This observation ought to chasten the most overzealous advocates of Darwinian social science, as well as softening the instinctive resistance of many social scientists and historians to the genuine insights enabled by a Darwinian approach. The conclusion discusses these insights, the most important of which is a methodological prescription for normative theory.
\end{abstract}

Keywords: cultural evolution, evolutionary economics, generalized Darwinism, adaptationism, natural selection 


\section{Introduction: the question of Darwinian social science}

In recent years, many have claimed to find Darwinian foundations for the study of human society and culture. ${ }^{1}$ Their core insight is that the logic of natural selection applies to human cultural practices as well as biological traits, and as a result, they argue, the sciences of biology and society are properly seen as subsets of a "generalized" or "universal Darwinism" (Aldrich et al., 2008; Schubert, 2014). At their boldest, these authors claim that a Darwinian perspective will revolutionize the study of human society by "facilitating a... synthesis for a unified science of culture" (Mesoudi, 2007: 253), thereby having "as great an impact on the social sciences as it has had on the biological" (Hodgson and Knudsen, 2010: x). This project is most often viewed with disdain and suspicion, however, by practicing social scientists and historians (Degler, 1991), who point to various disanalogies between human societies and biological populations as evidence that this sort of generalization is invalid (Bloch, 2012; Bryant, 2004; Hallpike, 1986; Ingold, 2007).

This paper seeks to clear the air in this heated debate by dissociating two claims which are too often assumed to be inseparable. The first is the "logical," "metaphysical," or "ontological" claim that Darwinian principles apply, at some level of abstraction, to human society and culture. The second is the more "pragmatic" claim that this observation necessitates substantial changes in the practices of social scientists. Even if some version of the first claim is true, I argue-which I believe is quite likely - the second does not follow. This ought to chasten the most overzealous advocates of Darwinian social science, as well as softening the instinctive resistance of many social scientists and historians to the genuine insights enabled by a Darwinian approach.

\footnotetext{
${ }^{1}$ This claim comes in many flavors. See, for example, the research programs of "cultural evolution," (Christiansen and Richerson, 2013; Laland and Brown, 2002; Mesoudi, 2011; Mesoudi et al., 2006; Richerson and Boyd, 2008) "social and economic evolution" (Hodgson and Knudsen, 2010) "social and cultural selection," (Runciman, 2009) and "sociocultural evolution" (Blute, 2010; Chase-Dunn, 2015; Sanderson, 2001). All build on relatively recent work (Blackmore, 2000; Boyd and Richerson, 1988; Dawkins, 1976; Hannan and Freeman, 1977; Nelson and Winter, 1982) and find inspiration in disciplinary founders as well (Alchian, 1950; Bagehot, 1872; Campbell, 1965; Darwin, 1859; Hayek, 1973; Morgan, 1877; Spencer, 1895; Tylor, 1873; Veblen, 1899).
} 
I assume with advocates of generalized Darwinism, in other words, that there is "a degree of ontological communality at a high level of abstraction" (Hodgson and Knudsen, 2010: 22) between human cultures and biological populations-i.e., that disanalogies such as the presence of "foresight" or "intention" in human affairs do not render the logic of natural selection irrelevant with respect to culture (Kronfeldner, 2006; Mesoudi, 2007; Sterrett, 2002). ${ }^{2}$ At the same time, however, the more diffuse skepticism of Darwinian approaches evinced by many social scientists and historians is understandable — and not only because of the (genuinely) appalling legacy of what has been (misleadingly) labeled "social Darwinism."” At least some of their resistance stems from the assumption that accepting such an "ontological communality" would invalidate their ordinary practices of inquiry, requiring them to adopt the methods and conceptual structure of biology instead. While many contemporary advocates of generalized Darwinism avoid making such extravagant claims about the practice of social science explicitly, few make much effort to deny them either, and suggestive promises about the revolutionary impact of synthesis and unification are widespread. ${ }^{4}$ Meanwhile, of course, plenty of fervent Darwinians have openly advocated the methodological "biologicization" of various humanities and social science disciplines at least since

\footnotetext{
${ }^{2}$ The idea of "ontological" communality is present throughout the literature on evolutionary social science (Aldrich et al., 2008: 579; Buenstorf, 2006: 513; Cordes, 2006: 529; Witt, 2004: 127).

${ }^{3}$ The term "social Darwinism" was applied, after the fact, to describe a number of deeply problematic social theories developed in the late $19^{\text {th }}$ and early $20^{\text {th }}$ centuries, which explicitly or implicitly sought support from biological theory (Hofstadter, 1944). Today, it is often understood more widely to include everything from the disasters of $19^{\text {th }}$ century racial science and $20^{\text {th }}$ century eugenics to the sexism which still characterizes some work in evolutionary psychology, and I use it here because it has this contemporary salience. As many others have noted, however, the theories in question were not actually Darwinian in any meaningful sense, and as a result, careful scholars of the period agree that it is not a particularly useful term (Bannister, 1989; Hodgson, 2004).

${ }^{4}$ The language of "unification," "synthesis," "universalization," and "generalization" is common to many of the more enthusiastic advocates of Darwinian social science (Blute, 2015; Mesoudi, 2010, 2011; Mesoudi et al., 2006; Rosenberg, 2015; Sanderson, 2015). More moderate advocates for evolutionary analysis in the social sciences, by contrast, tend to see its potential contribution as a collection of potentially useful tools, rather than as a unifying explanatory framework or a generalizable methodological paradigm (Lewens, 2002, 2015; Turner and Maryanski, 2015). As Turner and Maryanski note, "the enthusiasm with which many trumpet the coming of biology in the social sciences is, at the very least, overdrawn, and, at most, harmful to the social sciences" (Turner and Maryanski, 2015: 92) - not least because it prevents a broader uptake of Darwin's real lessons for social science.
} 
E. O. Wilson's Sociobiology (1975). It is no surprise, in other words, that the gulf of misunderstanding and mistrust continues to grow.

The inference from ontological to methodological communality, however-assumed at least implicitly by advocates and skeptics of Darwinian approaches alike-is fundamentally mistaken. The primary contribution of this paper, therefore, is to demonstrate that whatever ontological communality may exist between biological populations and human societies, existing approaches to the study of human society need not fear replacement or colonization: in the vast majority of cases, accounting for this ontological communality will simply recommend that social scientists and historians continue doing what they were already doing. ${ }^{5}$ Advocates of generalized Darwinism, therefore, ought to scale back their ambitions and their rhetoric, while skeptics ought to open themselves to the real, if limited, contributions of a Darwinian approach—some of which I indicate in the conclusion. It is precisely in order to enable wider appreciation of these lessons, indeed, that clarifying the limitations of a Darwinian approach is so important.

\section{Preliminaries}

The primary question at stake is whether social scientists ought to adopt a more explicitly Darwinian approach in recognition of the ontological communality between biological populations and human cultures. We may begin, then, by clarifying which social scientists we mean, and what a more explicitly Darwinian approach might look like. First, there are a number of social scientific disciplines in which Darwinian methods are already in use, and remain relatively uncontroversial. Few would argue against the use of phylogenetic methods, for example, in tracing the historical

\footnotetext{
${ }^{5}$ In doing so, it takes up the suggestion of Aldrich et al. (2008: 592) that one legitimate critique of the "generalized Darwinism" they defend is that concepts of variation, inheritance and selection are simply not particularly useful when applied to social phenomena. Guido Buenstorf (2006) provides a similar argument, though it is limited to certain applications in economics.
} 
lineages of material artifacts and linguistic practices (Mace and Jordan, 2011). Social scientists using these methods need not be convinced to do so by being shown a particular ontological communality between biology and society—rather, these methods appear self-evidently useful for reasons which are internal to the goals of their discipline. For those who see all importation of biological methods into the social sciences as an unwelcome effort at colonization, this should serve as a first note of caution. Since these methods are already in wide use in the fields where they are relevant, however, adopting them would not substantially change the practices of social scientists, and so it is not directly relevant to the matter at hand.

I will also set aside the question of evolutionary psychology. Though many applications of evolutionary psychology are highly controversial, few serious social scientists would question the methods of evolutionary biology as such, nor even their applicability to the human brain. Serious critics may charge, of course, that evolutionary psychologists draw systematically overconfident generalizations about "human nature" based on unsubstantiated speculation, and therefore serve only to provide convenient justifications of the contingent power relations which have created the regularities they seek to explain. If there is biological imperialism at work here, however, it is happening at a substantive and not at a methodological level. Evolutionary psychologists do not contest the methods of social science in any general sense, that is; they simply claim that certain particular practices are inherited traits rather than cultural constructs, and are therefore best understood with the methods of evolutionary biology rather than those of social science. Though the controversies over such claims are important, I will not address them here, instead confining my scope to social science qua social science: i.e., the study of whichever human practices are properly studied as cultural constructs. 
Notwithstanding these exceptions, what I have called "social science" or "the study of society" encompasses a very wide range of cultural, social, and historical inquiry —including many of the practices of historians, cultural anthropologists, and social and political theorists as well as economists, political scientists, and sociologists - on the assumption that there is a common motivation behind all of this inquiry. Whether it is the political scientist studying why people adopt liberal or conservative ideologies; the sociologist seeking to understand patterns of educational attainment; the anthropologist grappling with the religious customs of an unfamiliar culture; or the historian tracking the spread of revolutionary ideas in $18^{\text {th }}$ century France; nearly all "social scientists" in this broad sense are asking questions about why people engage in particular cultural practices as opposed to others. ${ }^{6}$

There are, of course, great disagreements within and among these disciplines, both about the substantive answers in particular cases, and about the right methods for arriving at those answers in general. One potential contribution of Darwinian social science, then, might be to resolve these disagreements, and indeed, this claim has been made by a number of its advocates. Alex Mesoudi, for example, argues that acknowledging the ontological communality between biology and society requires abandoning the "non-scientific, post-modernist approach that has taken hold in many branches of the social sciences and humanities," (Mesoudi, 2010: 1), and adopting extensive formalization and quantification instead (Mesoudi, 2011: 205-6). These arguments, however, are underwhelming. Even if a Darwinian approach could be shown to support one side in long-

\footnotetext{
${ }^{6}$ I have generally avoided the word "explanation" here, since this is a term of art among philosophers of science, and many social scientists see themselves as engaged in "analytic narratives" (Bates et al., 1998) or "process tracing" (George and Bennett, 2005) or "thick descriptions" (Geertz, 1973) rather than explanations in the strictest sense. Nevertheless, all who are included in my scope are at least implicitly engaged in a practice that is plausibly understood as offering partial answers to questions about why people engage in certain practices as opposed to others. The definition of "culture" can also be controversial, and though I cannot avoid using the word, I can clarify how I am using it. By "cultural practice," I simply mean to indicate any behavior that human beings learn from one another, and when I refer to a group of human beings as a "culture" or "cultural group," all I mean is that they share a significant number of cultural practices in common.
} 
standing controversies about the proper role of quantification, this would not simply settle those controversies once and for all. Moreover, many who recognize the ontological communality linking biology and social science take nearly the opposite lesson from it, rejecting universalizing formal or quantitative ambitions in favor of attention to local context and particular developmental histories (Blute, 1997; Rosenberg, 2015: 36-42).

Some advocates of Darwinian approaches to social science, finally, make few if any claims about whether and how social scientists should change their practices, emphasizing the conceptual shift entailed by recognizing that social scientific methods have been biological all along. If this is really all that is claimed, then I have no objections, and indeed, I will suggest a few consequences of this conceptual shift in the conclusion. For many advocates of generalized Darwinism, however, adopting a Darwinian approach is supposed to do much more than this: it is supposed to provide better answers to the kinds of questions social scientists ask, regarding why people engage in particular cultural practices as opposed to others. The most promising contribution of the Darwinian approach in this regard, then, is what I shall call the "adaptationist heuristic," and I turn to it now.

\section{Adaptationism in biology and society}

Darwin's most basic insight is that variants in nature enjoy differential success in achieving basic goals like survival, growth, and reproduction, and that those which are most successful overall tend to proliferate at the highest rates. This overall successfulness we understand as "fitness," which in turn allows us to discuss the "adaptiveness" of individual traits. A trait is adaptive, we say, if it increases fitness, maladaptive if it reduces fitness, and fitness-neutral

otherwise. Taken together, these observations explain why many biological organisms appear to be so well adapted to their environments: while traits that are maladaptive are eventually 
eliminated from populations, those traits that are still around for us to observe have often survived because they are adaptive, or because they enable some other adaptive trait.

Of course, not all traits that we observe are currently adaptive. Traits that were once adaptive or fitness-neutral, for instance, may have been rendered maladaptive by changes in the environment, and simply not had time to be selected out of the population, while others may be the result of recent mutations. Still others, finally, may be genuinely fitness-neutral, in which case their frequency in the population changes randomly over time in a process called "drift." Indeed, there is great controversy among biologists and philosophers about both the prevalence and the importance of selection in nature, relative to drift and other processes. ${ }^{7}$ As a result, biologists do not simply assume that all traits are adaptations-i.e., the result of selective pressures - rather, their task in understanding any particular trait is to figure out which of these processes is responsible for its persistence. In most cases, however, the relevant options are selection and drift. Thus, the possibility that the trait is fitness-neutral — and therefore owes its persistence to drift alone-functions as something of a "null hypothesis," providing a default for cases where there is no creditable explanation in terms of some present or historical adaptive function.

What I call the "adaptationist heuristic," therefore, is a way of generating alternative hypotheses, which directs biologists to consider whether the phenomena they seek to understand might be adaptations that increase the fitness of some unit of selection; and if so, how they achieve this effect. As others have observed, this heuristic is not particularly useful unless we understand something about what causes particular variants to proliferate at higher rates than their competitors

\footnotetext{
7 These debates are quite extensive, and as explained below, I seek to avoid making the conclusions of the paper dependent upon any particular position within them. The locus classicus for the critique of adaptationism is Gould and Lewontin (1979), and for further discussion, see Brandon (1990), Dennett (1996), Godfrey-Smith (1999, 2001), and Lewens (2008). In particular, Godfrey-Smith (2001) provides a helpful breakdown of three kinds of adaptationism - empirical, explanatory, and methodological—which roughly correspond, respectively, to claims about what I call the "prevalence" of adaptation, its "importance," and how often an adaptationist heuristic ought to be adopted. As I clarify below, I consider the first two to be "ontological" claims, and the third as a "pragmatic" claim.
} 
in a particular environment. ${ }^{8}$ Fortunately, there are a limited number of selective pressures which guide biologists using the adaptationist heuristic in any given situation. In studying animal behavior, for instance, many adaptations can be understood with reference to their role in fulfilling a few key functions such as finding food, avoiding predators, and reproducing with high-quality mates - and these have analogues in other branches of biology. As we have acknowledged, of course, any adaptationist hypothesis must be evaluated in light of the available evidence and compared to the "null hypothesis" of drift. Nevertheless, few would dispute that this heuristic has often been highly productive, enabling biologists to generate specific, novel hypotheses about the origins and functions of biological phenomena, many of which are supported by the evidence. It therefore allows biologists to go beyond the default assumption that their persistence is entirely random.

For the purposes of a biologist studying the natural world, of course, confirming the null hypothesis of random drift is perfectly satisfactory. For social scientists and historians studying human societies, however, this answer will typically be unsatisfying: even if the persistence and proliferation of a cultural practice is random with respect to selective pressures, there is still much more to say about why people engage in particular practices as opposed to others. That is why a cultural version of the adaptationist heuristic is by far the most promising contribution of a Darwinian approach in the social sciences. Where confirming the Darwinian's null hypothesis of random drift adds nothing to our existing understanding of the persistence and proliferation of cultural practices, a cultural adaptationist heuristic — which considers the possibility that cultural

\footnotetext{
${ }^{8}$ Since the "fitness" of any given variant refers to its propensity to proliferate, this has sometimes been seen as a "tautological" law (Smart, 1959). This is incorrect, since it posits a pre-existing propensity to proliferate as an explanation of actual proliferation (Mills and Beatty, 1979; Rosenberg, 1983); what we can say, however, is that the law is not particularly useful unless we supply some additional information about what sorts of things might increase the fitness of a particular variant within its particular ecology.
} 
practices are adaptations as a way of generating specific, novel hypotheses about their origins and functions - could, it seems, improve upon that understanding.

The key question in debates about whether Darwinian insights will substantially change the practices of social scientists, therefore, is whether and how often an adaptationist heuristic can be adopted towards social and cultural practices. Advocates claim, on the one hand, that the logical, metaphysical, or ontological communality between biology and culture justifies widespread use of this heuristic (Blackmore, 2000; Dennett, 1996; Mesoudi, 2011; Rosenberg, 2015). Skeptics, on the other hand, point to various disanalogies between biological and cultural "evolution" as evidence that this ontological communality is non-existent or weak, and so regardless of how often it turns out that an adaptationist heuristic is justified in biology, it will much more rarely be justified in social science (Buenstorf, 2006; Cordes, 2006; Foster, 1997; Sperber, 2000; Witt, 2004). ${ }^{9}$

As noted in the introduction, this paper adopts a different approach. Rather than arguing that adaptationism is never or rarely justified in social science, I shall argue that it is rarely useful; i.e., that even if the social practices they seek to understand are adaptive in an ontological sense - and are therefore best explained on some fundamental level by underlying "unrestricted Darwinian regularities" (Rosenberg, 2015)—social scientists need not substantially change their normal practices of inquiry to account for this fact. ${ }^{10}$ My strategy is neither to deny nor to defend any particular account of ontological communality between biological populations and human societies, but rather to dissociate all ontological claims from the pragmatic recommendations which are often said to follow for social scientists. In order to provide an argument which is robust

\footnotetext{
${ }^{9}$ These two camps are inevitably drawn too starkly, as there is substantial disagreement within each. Moreover, only a few self-consciously adopt the language of "adaptation." Nevertheless, for the purposes of this paper, this is a fair characterization of the views cited as well as the tenor of the debate more generally.

${ }^{10}$ In Godfrey-Smith's (2001) terms, I accept the strongest version of "empirical" and "explanatory" adaptationism with regard to society - ontological claims - in order to evaluate the pragmatic claim that we should adopt a certain form of "methodological" adaptationism in the social sciences.
} 
to legitimate disagreement about both the prevalence of adaptation in biology and the level of ontological communality between biology and society, therefore, I simply presuppose the strongest account of both. Following Alexander Rosenberg (2015), I take for granted that all social practices of interest to social scientists are adaptations, arguing that even given this extravagant account of the prevalence and importance of Darwinian adaptation in human society and culture, social scientists need not substantially change their practices of inquiry. ${ }^{11}$ And since the null hypothesis of random drift does not help social scientists understand the persistence and proliferation of cultural practices, we can assume that a Darwinian approach will be even less useful to the study of society if it turns out that not all cultural practices of interest are adaptations.

Rather than highlighting essential ontological differences between biological populations and human cultures, therefore, this argument draws upon contingent epistemic differences which render an adaptationist heuristic less useful for social scientists. First, there is a much greater variety of selective pressures operating on cultural practices, which complicates the problemalready complex in biology — of sorting out the causal contribution of competing selective forces. The standard of evidence for particular adaptationist hypotheses, therefore, will be higher. Gathering this evidence, however, will be more difficult in social circumstances, since we cannot do controlled experiments on many variables of interest. This is also true of evolutionary biology in certain circumstances, but this leads us to the third point: when we can provide good evidence

\footnotetext{
${ }^{11}$ We can use Rosenberg's account as a proxy for the strong ontological assumptions I take for granted. It begins by asserting that "all significant features of human affairs...have functions," that "functions are all adaptations," and that "the only sources of adaptation in nature... are Darwinian processes of blind variation and environmental filtration" (i.e., natural selection). Next, he claims that both biological and social regularities represent "local evolutionary equilibria, which are eventually broken up by "arms races." They are therefore "restricted, limited in their spatiotemporal domains," and must "draw their explanatory power from underlying unrestricted Darwinian regularities." Finally, Rosenberg surmises that social science must "proceed by explicitly Darwinian research strategies - identifying adaptations and the processes that determine their emergence, proliferation, persistence, and extinction" (all quotes Rosenberg 2015, 32). It is only when we come to this final claim that we find any mention of direct consequences for the practices of social scientists, and it is therefore only this final claim that I contest.
} 
that a particular adaptationist hypothesis is true, this will largely replicate our existing understanding of the practices in question. Unlike biologists studying unfamiliar biological phenomena, we have intimate experience with cultural practices, having witnessed and recorded their development throughout history.

In other words, we have likely already entertained most hypotheses about cultural practices that can be generated by an adaptationist heuristic, and either accepted them in non-Darwinian terms, rejected them as being unsupported by the evidence, or postponed judgment about them until further evidence is available. In all of these cases, adopting an adaptationist heuristic simply tells social scientists to do what they are already doing. If this means that the social sciences are biological in character, and perhaps always have been, so be it. But this does not mean that a Darwinian approach will be particularly useful for social scientists, recommending a substantial change in their practices.

I develop this argument by considering three concrete ways of applying an adaptationist heuristic in social science: biocultural evolution, which refers to the ways in which cultural practices increase the biological size of a coherent cultural group; sociocultural evolution, which refers to any of the other ways in which cultural practices may be said to have increased fitness; and economic evolution, a particular variety of sociocultural evolution which highlights the market as a particularly well-understood selective pressure. Each has its own strengths and weaknesses, but each ultimately faces the same tradeoffs between novelty and plausibility.

\section{Biocultural adaptationism}

The first problem that social scientists face in adopting an adaptationist heuristic is that there are simply too many selective pressures in play, and therefore too many ways in which a cultural practice might be "adaptive." Recall that an adaptationist heuristic is not very useful unless we 
know something about what might increase the fitness of variants in their environment. It becomes useful to biologists when it directs their attention towards a few key intermediate mechanisms, responding to a few key selective pressures: in animal biology, for instance, these are functions such as finding food, avoiding predators, and reproducing with high-quality mates, whose connection to fitness is well understood. Biologists might also search for other functions, of course, including proximate functions such as homeostatic regulation or structural integration which enable these primary functions, but there are nonetheless a limited number of mechanisms which "fill in" the details of an otherwise unhelpful heuristic, rendering it practically useful. If an animal biologist cannot plausibly connect a trait to one of these well-understood mechanisms, therefore, she will be at a loss as to how it is an adaptation, and may settle for the "null hypothesis" of drift instead.

The promise of biocultural evolution is therefore that it suggests a number of mechanisms which are similarly well-understood, responding to a number of constant selective pressures facing human cultural practices. Indeed, we can even draw parallels to the functions of food acquisition, predator avoidance, and finding mates which are prominent in animal biology, such as agricultural productivity, military capacity, and reproductive fecundity. The most obvious of these mechanisms is straightforward biological reproduction, ${ }^{12}$ but this is only one of the ways in which individuals can be added to the ranks of a cultural group or sub-group, and I also use the term to refer to other ways by which a group assimilates new individuals, such as military conquest or voluntary

\footnotetext{
${ }^{12}$ Of course, it is not a given that biological reproduction should help spread cultural practices. In practice, we observe that most children do adopt the cultural practices of their biological parents; however, if biological children were to leave their parents at an early age and join a different culture, we would expect them to adopt the cultural traits of their cultural group instead. Relatively coherent cultural groups - which may be as small as a family or as large as a society - are therefore the primary locus of "heredity" in cases of biocultural evolution. A cultural practice which increases the reproductive fitness of individuals becomes part of this recursive Darwinian process not primarily by replicating the practices of those individuals but by expanding the coherent cultural group to which those individuals belong.
} 
entrance. Thus, a social scientist might argue that irrigation improves agricultural productivity, which explains why the Sumerians were able to grow faster than rival groups; or that facility on horseback improves military capacity, which explains why the Mongols were able to conquer much of Asia; or that certain conservative religious norms lead to high birthrates, which explains why groups such as the ultra-Orthodox in Israel are growing in size and importance relative to other sectors of Israeli society.

The trouble with these observations, of course, is that they are obvious. Among those studying the development of ancient human cultures, many already explicitly adopt a Darwinian framework, while many others consider Darwinian logic implicitly. In these sorts of cases, I argue-where biocultural population logic is implicit in the explanation - then adopting Darwinian concepts explicitly will not contribute much to our understanding. It may be logically, metaphysically, or ontologically justified, in other words, but it will not be particularly useful. We can use a Darwinian framework for understanding how these stories fit together, but this does not substantially change the practices of social scientists, who had of course already observed that civilizations with more advanced agricultural and military technology tend to outcompete other civilizations; and that high birthrates among cultural subgroups, all else equal, tend to increase the size and influence of those cultural subgroups.

A second problem, then, is that all else is never equal. In fact, there are inevitably many, many other selective pressures operating on cultural practices, even if we temporarily limit our attention to biocultural evolution. Think, for example, of the billions of people who assimilate voluntarily into other cultures or subcultures - Ghanaian immigrants resettling in the United States, or Muslim youth in France traveling to Syria to join ISIS, or queer youth from small conservative towns joining subcultures in cities such as New York and San Francisco. Ontologically, these can be 
understood as cases of biocultural evolution, with relatively coherent cultural groups adding biological individuals to their ranks, and so we can assume that certain of their practices are responsible for their high rates of assimilation.

Pragmatically, however, an adaptationist heuristic does not add anything to our toolkit, for it is unclear which practices these are, and how they are achieving this effect. We can provide many halfway plausible adaptationist hypotheses: perhaps it is the economic opportunity offered by capitalism in the United States which attracts people to immigrate; perhaps it is the rejection of Western capitalist modernity which attracts people to join ISIS; perhaps it is the rejection of traditionalist norms which attracts people to join queer subcultures. Each of these hypothesized "selective pressures," however, clearly contradicts the others. This is not to say that they do not all exist, but it is difficult to know which ones are operative at any given time and place, not to mention how strong they are relative to all of the other selective pressures which may or may not exist. Expanding our analysis to include "sociocultural" mechanisms makes this problem even more intractable.

\section{Sociocultural adaptationism}

Where biocultural evolution governs cultural practices which spread via the biological expansion of a cultural group, sociocultural evolution describes practices that spread via lateral transfer rather than the wholesale expansion of a cultural group, thereby using cultural mechanisms of "reproduction" or proliferation as well. ${ }^{13}$ Precisely because it is not limited in this way, sociocultural evolution has often generated the most enthusiasm among advocates of Darwinian

\footnotetext{
${ }^{13}$ There are a number of ways of classifying the varieties of cultural evolution, including those in Laland and Brown (2002) and Mesoudi (2011). Mesoudi's categorizations (p. 57) are particularly comprehensive, and throughout the paper, I discuss many of the finer distinctions he makes in different terms. However, I have selected these broader categories of analysis because they represent the most important differences in explanatory method. What I call biocultural adaptationism is spread across Mesoudi's categories of "natural selection" and "demic diffusion"; what I call sociocultural adaptationism covers nearly everything else.
} 
social science, but this open-endedness only exacerbates the problems we have already examined in the case of biocultural evolution. We can see this more clearly, then, by considering each of Alex Mesoudi's (2011: 57) three main sociocultural selective pressures: "model" biases, "content" biases, and "frequency-dependent" biases.

Model bias names the tendency of people to copy the practices of certain "models" who are seen as attractive targets for copying for some reason or other. "Prestige" biases, for instance- $\mathrm{a}$ subset of "model" biases - occur when people adopt the practices of those with high social prestige. Given this bias, if a practice tends to increase the social prestige of its practitioners, then it can be said to enhance their fitness by means of increasing the practitioners' "cultural fecundity"- making all of their practices more visible and more attractive as a target for copying. The practice therefore counts as a fitness-enhancing, functional adaptation, which is likely to spread throughout the population.

This is true as far as it goes: to whatever extent a practice makes one more prestigious, it will probably gain adherents who also desire prestige. Yet a Darwinian approach adds little if anything to our understanding here. In order to demonstrate why people have adopted a particular practice in a particular environment, we must know, first, why people adopt the practices of prestigious individuals in this particular case, since they do not do so in all cases. We must also know, of course, why a particular practice is considered prestigious in the first place. A Darwinian approach making use of prestige bias simply predicts that, once these two pieces are in place, people will likely adopt the prestigious practice. The adaptationist heuristic simply urges us, therefore, to ask why a particular practice is prestigious in particular circumstances. But this is exactly the sort of question already being asked by those attempting social, cultural, and historical inquiry. By reminding us to ask it, the Darwinian perspective adds little. 
Content biases do not fare much better. According to Mesoudi, a content bias favors a practice when that practice has some internal characteristic which is particularly attractive. Rather than affecting the fitness or cultural fecundity of the host individual in a more general sense, therefore, it directly increases the reproductive fitness of the practice itself. At the risk of beating a dead horse, we might consider the usefulness of content biases through the example of the ill-fated science of memetics (Blackmore, 2000; Dawkins, 1976). Many critics of memetics tried to discredit it by identifying ontological disanalogies between particulate, high-fidelity gene transmission and the more chaotic processes of cultural transmission (Laland and Brown, 2002: chapter 6). Rosenberg effectively defuses such ontological critiques (2015: 42-49), but as we are now able to appreciate, the real problem with memetics as a science has always been with its pragmatic usefulness rather than its ontological basis.

It may be true, that is, that the "memes" (or "strategies" or "routines" or "practices") with the highest propensity to proliferate do end up proliferating at the highest rates, but this still does not give us any novel clues about what contributes to their propensity to proliferate in the specific ecological circumstances we are analyzing. In order to get beyond this platitude, a Darwinian approach must offer some practical guidance about what sorts of features will help particular practices in particular cultural environments get copied. Content-bias analysis makes the empty claim that content towards which people are biased will be adopted at higher rates, while leaving the only interesting question unanswered: i.e. why do people happen to be biased towards that content in the first place? This, again, is exactly the question social scientists and historians have always asked: why do people engage in particular cultural practices as opposed to others?

Finally, we may consider "frequency-dependent" biases, which occur when people adopt practices that occur with a certain frequency in the general population. This has been observed 
most obviously in psychological and sociological studies about conformity (Asch, 1951), but it can also be responsible for more complex dynamics such as "cascades," which have been welldocumented in economics and political science (Kuran, 1989; Kuran and Sunstein, 1999). Even moreso than the other biases we have analyzed, however, frequency-dependent biases seem to have very little connection to a specifically Darwinian approach. At least with "model" and "content" biases, we could hypothesize a particular fitness-enhancing adaptation which was inherent to the practice itself, either through its effects on its hosts or its attractiveness to others. In the "frequency-dependent" case, by contrast, there is no local determinant of fitness whatsoever - the "fitness" of the practice is entirely dependent on the environment.

This returns us to the "second-order" problem highlighted above, concerning how to choose between various hypotheses suggested by an adaptationist heuristic. So far, we have remarked that the mechanisms pointed to by advocates of pure sociocultural evolution are not very specific about what sorts of adaptations to look for. This problem looms even larger when we consider that in any given situation, when social scientists are seeking to understand why people have adopted a particular cultural practice, we do not even know which kind of fitness to consider. People will presumably adopt prestige, content, and frequency-dependent biases at different times and places, but we are given no special guidance about when to apply which mode of analysis. Moreover, in any normal situation, people exhibit a number of biases at once, meaning that there are a number of types of fitness in play, each of which may present different selective pressures.

Regardless of how plausible any particular hypothesis about the importance of a selective pressure might be, in other words, how can we sort out which selective pressures predominate in which places, for which people, and which times? As we observed above in the case of biocultural evolution, teasing out the relative causal contribution of various factors to the production of a 
social phenomenon is extremely difficult to achieve in the dynamic, complex, causally dense circumstances characteristic of culture. This task will perhaps only become ever more difficult as the prevalence of lateral transfer and the speed of cultural change increases with the globalization and acceleration of capitalist modernity.

\section{Evidence of adaptation in biology and society}

There are of course dynamic, complex, and causally dense circumstances in biology, and sure enough, biologists also have great trouble teasing out independent causality in cases where multiple selective pressures point in different directions. The difference, however, is that biologists typically need to consider only a limited number of pressures at any time, for there are only a limited number of means by which biological units of selection can reproduce themselves. Animal reproduction, for instance, primarily involves high-fidelity genetic replication, sexual recombination, and epigenetic modulation. There may be cases of lateral gene transfer, and these and other mechanisms may be more prevalent in other branches of biology, but in any given context, a few concerns will reliably predominate. Moreover, these pressures will be relatively constant within a particular biological context: animals will not stop needing to acquire food, avoid predators, or find mates, in order to pass on their traits to offspring.

All of this makes the task of sorting out the causal influences of any particular selective pressure acting on biological phenomena quite a bit easier than it is in society, where as we have seen, there are not only a number of different biocultural and sociocultural means of proliferation, but a vast array of potentially active selective pressures. Only a few are guaranteed to be activemostly the basic biocultural mechanisms involving food, fecundity, and coercive capacity—and even these are not guaranteed to be particularly important relative to others, especially in the modern era. This discussion therefore highlights the first major epistemic difference between 
biology and social science: because the number of ways in which social practices can be "adaptive" is nearly unlimited, the hypotheses generated by an adaptationist heuristic will be much less specific, and the burden of proof for any given hypothesis will be harder to meet.

Moreover, biologists have another very significant advantage over social scientists in teasing out causal relationships despite enormous causal density and complexity, which is the ability to run controlled experiments. For obvious reasons, this is the gold standard in causal inference across the sciences, but in studying human society, this method is severely limited by both practical and ethical concerns. Though we can feasibly and sometimes ethically run experiments in psychological laboratories testing very specific behavioral responses to certain practices, these experiments cannot be assumed to have external validity with respect to the overall fitness of complex practices within complex ecologies.

Social scientists have begun doing "field experiments" to test the effects of specific interventions, of course, while "evidence-based policy" and "randomized controlled trials" (RCTs) have become the buzzwords of governance, philanthropy, and international development in recent years. Such trends have stark limits, however: the more generalizable and important the question, the more infeasible and unethical the requisite experiment becomes. Consider the insurmountable practical and moral barriers, for instance, to "random assignment" of religious practices or social norms; not to mention race or gender. Clearly, the experimental method which is so central to teasing out causality in the face of complexity for the physical and life sciences is unlikely to provide much supporting evidence for Darwinian hypotheses about the relative causal impact of various selective pressures on the evolution of human cultures.

In the absence of controlled experiments which might support adaptationist hypotheses in culture, we are left to consider the evidence of the "natural experiments" of history. In evolutionary 
biology, of course, this is also our best option in many circumstances, and it can indeed justify certain biocultural adaptationist narratives. Despite all of the challenges to sorting out the causal impacts of various pressures on the proliferation of cultural practices, for instance, we have already allowed that irrigation, horseback riding, and traditional religious norms mandating high birthrates can be viewed as "adaptations" which have caused the growth of cultures adopting them, and it is historical evidence which supports such claims. When taking a very broad view of history, therefore, an adaptationist heuristic can help us understand why it is not terribly surprising that agricultural practices have become more and more efficient over time, nor that effective military technologies have spread around the world as a result of recurring "arms races"- a potentially useful observation, to which I will return in the conclusion. Similarly, the tension between the biocultural selective pressures favoring high birthrates and whatever other biocultural or sociocultural pressures favor low birthrates is one that will likely play an important role in the future evolution of global society.

The final difference between biology and society, however, is that as participants and observers, we are intimately familiar with the practices under discussion, and therefore, we are often already well aware both of the hypotheses themselves, as well as the evidence which may or may not be available to support them. In some cases, of course, the evidence is already strong enough to justify acceptance of the hypotheses in question - as when viewing irrigation and advanced weaponry as "adaptations" — but the Darwinian framework does not greatly enhance our understanding of why people engage in those practices as opposed to others. In other cases, the hypotheses in question require more support before they can be accepted, as with our adaptationist narratives about immigration flows, ISIS, and queer subcultures, and generating them might push us to search for further evidence which could confirm them. As these examples suggest, however, 
generating hypotheses is not typically the problem in social science and history: rather, the problem is choosing between them.

There is no general agreement among particular social scientists about how to solve this problem, of course, nor even about how to describe it: each discipline asks particular questions in particular ways, and has a particular style for answering those questions. Throughout socialhistorical inquiry, however, the central methodological and historiographical question is how to decide which among the vast array of potentially important factors involved in the production of any particular social phenomenon are the most important. Reframing social phenomena as "adaptations" and the causal factors in their production as "selective pressures" simply underscores the importance of this question, without giving us new tools for answering it.

\section{Evolutionary economics}

As a final illustration of these issues, let us turn to evolutionary economics, which seeks to improve upon conventional understandings of economic processes by employing either analogical (Nelson and Winter, 1982) or ontological (Hodgson and Knudsen, 2010) communalities between natural selection in biology and the "selective" pressures of economic markets. ${ }^{14}$ Though it is technically a variety of sociocultural evolution, economic evolution refers to a specific and wellunderstood intermediate mechanism, like those available to biocultural evolution, which increases the "fitness" of cultural practices. It might therefore seem to transcend the limitations of other uses

\footnotetext{
${ }^{14}$ Many of these authors distance themselves from what they understand as the "adaptationism" of early evolutionary economists like Milton Friedman and Oliver Williamson, which assumes that all outcomes in a Darwinian process must be "optimal" relative to a particular selective pressure such as "profit-maximization." In this extremely narrow sense, then, they are not adaptationists, and neither are any serious contemporary advocates of generalized Darwinism. They do, however, make use of what I have called the "adaptationist heuristic"-i.e., analyzing cultural practices as responsive to a range of selective pressures, while also accounting for the possibility of drift—which describes a much broader variety of research practices and assumptions.
} 
of Darwinian concepts in studying human cultural practices, and indeed, it is the best-developed case of evolutionary analysis in social sciences.

To understand how economic markets exert selective pressure on firms, consider first the case of an efficient widget-producing machine, which produces greater output with fewer inputs, yielding a higher rate of return on investment. Under normal circumstances, this high rate of return will attract investors, growing those companies that use the machine and inducing other companies to adopt it. The machine spreads as a result of its contribution to the efficiency of firms, in other words, and can therefore be considered an "adaptation." Since these dynamics are clear to everyone involved, however, adopting an adaptationist perspective is not useful here. There is no mystery to be solved as to why companies use more efficient machines if they can: rational entrepreneurs will choose to use more efficient machines if the cost they save is greater than their price. Indeed, this is precisely the logic employed by conventional economists, and adopting a Darwinian approach would not change their practices at all.

The innovation of evolutionary economics, then, is not to explain how the market causes the proliferation of efficient machines, whose efficiency is well understood. Rather, it is to shed some light on those features of efficiency that are not immediately obvious, such as the organizational structure of firms — or in Nelson and Winter's (1982) terms, their "routines." The market helps us understand how a particularly efficient routine or organizational structure may proliferate — when a firm's profits go up, this leads to capital investment, which in turn leads to expansion, branching, spin-offs, and mimicry - even if no one recognizes precisely what it is about that structure which makes it efficient. This general observation chastens overly rationalistic conventional economists who, upon observing that firms often seem to behave "rationally," assume that their executives must be rational, skilled, and well-informed decision-makers. As Armen Alchian (1950) and others 
have pointed out, this is an unrealistic assumption, and a Darwinian perspective reveals it to be superfluous. The firms that survive often do make rational choices, the argument goes, but not because of the intentional choices of rational executives: rather, unlucky firms are simply outcompeted by those that have lucked into efficiency. ${ }^{15}$

This chastening, however — while undoubtedly important—is more of a cautionary note and a call for a humility than a substantive statement about how people should go about answering questions about why individuals and firms engage in particular practices as opposed to others. We are directed to find the ways in which various practices contribute to the efficiency of firms, but given little guidance as to which these are, or how we might find out (Buenstorf, 2006). Doubtless, successful firms $d o$ have adaptive practices which contribute to their efficiency, which in turn leads to the proliferation of those practices. Various adaptationist stories can be told, and given our strong ontological assumptions, one of them must be correct. Adopting an adaptationist heuristic does not point our attention in any specific direction, however; it simply points our attention away from the decisions of executives, reminding us that there might be other reasons for the success of firms. The trick, of course, is to find which of these practices are actually efficient, and which have survived for other reasons. And this, to use a refrain of the paper, is precisely what those studying business practices— both within and outside of the academy — are already trying to do. Indeed, a great deal of money and power is at stake in the answer. A heuristic which tells us only to go out and look for what makes efficient firms more efficient is not a very useful addition to our toolkit as social scientists or investors.

\footnotetext{
${ }^{15}$ As suggested above, the arguments of Alchian and others on this point have often been focused on a particular theory of firms as "profit-maximizing" entities, using Darwinian terms to vindicate theses of optimality. As critics have rightly demonstrated, however, profit maximization is not the only selective pressure acting upon firms, and so assumptions of optimality in that respect are unwarranted (Winter, 1964). For this reason, I have avoided the language of "profit-maximization" and emphasized the broader point that a Darwinian perspective allows us to understand how practices which are "successful" or "efficient" in some more general sense can spread more quickly than others, even if no rational agents are directing that process.
} 
The question with which we began is whether social scientists should explicitly adopt a Darwinian approach, given that we accept the ontological communality between biological populations and human societies. I have argued, then, that in most cases, adopting this heuristic towards cultural practices simply recommends doing what social scientists are already doing. Social scientists are already pursuing practices which are compatible with an ontological communality between biology and society, that is, but explicitly adopting the Darwinian concepts of adaptation, fitness, and selection pressures will not often improve upon those practices. Once we have dissociated ontological claims of communality between biology and society from pragmatic claims about the methods which should be adopted by social scientists, however, we can begin to appreciate the more important lessons a Darwinian approach might teach us. Social scientists who are reticent to don Darwinian lenses out of fear that doing so will require them to replace their customary conceptual structures and methodologies with those of biology, in other words, can begin to see what those lenses actually reveal-and I will close with some suggestions about what that might be.

\section{Conclusion: When can a Darwinian approach be useful?}

Throughout this paper, I have assumed a particularly strong account of ontological communality, inspired by Alexander Rosenberg (2015), according to which most if not all social practices of interest to social scientists are adaptations in a Darwinian sense. Though I reject his conclusion that social science must "proceed by explicitly Darwinian research strategiesidentifying adaptations and the processes that determine their emergence, proliferation, persistence, and extinction" (32), I find another feature of his account more compelling, which is that all biological and social regularities are "local equilibria" which will eventually be broken up by "arms races": 
“As in biology, each individual's or group's adaptation sets a design problem for the individuals and groups with which it finds itself in local equilibrium. The existence of these mutual design problems together with the persistent but blind variation among adaptations means that the prospects for arms races are ever present. Beneath every local equilibrium there is a seething rumble of blind variations continually being tested by and testing the local equilibrium. The latter must always eventually be broken up by one of these variants that precipitate an arms race. Whence the restricted character of every explanatory regularity and all the models in social science" (39).

If social regularities are local equilibria between practices and strategies, in other words, which are always in danger of being invaded by more adaptive variants, then all of the purported "regularities" in human society that have been described by social scientists are dependent upon a limited environmental context and subject on some level to disruption. Just as it did for overly rationalistic versions of conventional economic theory, in other words, adopting a Darwinian approach to human societies more generally cautions social scientists to exhibit greater humility about the universality and precision which are possible in their work. Some regularities are relatively robust, of course-Rosenberg's example is that democracies do not go to war with one another-but even in these cases, a Darwinian perspective highlights their fundamentally limited character, encouraging greater awareness of and attention to the environmental changes which could conceivably upset those regularities. 
Humility about empirical regularities is, of course, an important lesson for social scientists to learn. It seems to me, however, that the normative lessons of a Darwinian perspective are even more important, and there are two in particular that I would like to discuss. First, where social theorists have often assumed that human institutions which are clearly "adaptive" or "functional" in some way must also be beneficial to someone — or even to society as a whole—a Darwinian approach exposes this inference as everywhere and always invalid. Such practices may be beneficial to society as a whole, but this is by no means necessary or even likely—indeed, most practices are beneficial only to a particular group, and some may even be beneficial to no one at all. On a Darwinian framework, all we can say about adaptive practices is that they benefit themselves in some way. While others have appreciated these insights without explicitly applying a Darwinian framework, the temptation to assume that existing social institutions represent an "optimal" or at least "locally optimal" solution to some problem is surprisingly stubborn, even among social scientists who should know better. ${ }^{16}$ Recognizing the ontological communality between biology and social science should forever rid us of this temptation.

Second, and perhaps even more significantly, recognizing this communality highlights the inadequacy of certain moral and political responses to cultural practices which are harmful but adaptive, giving political theory an important methodological agenda. Consider the cultural practices explored above as examples of biocultural adaptation, including efficient agricultural techniques and advanced military technology. Ontologically, I argued, it is probably legitimate to understand these practices as adaptations relative to important biocultural selective pressures, yet doing so does not provide us with any novel hypotheses about their persistence and proliferation: it is not exactly news that societies with such practices have tended to expand more rapidly than

\footnotetext{
${ }^{16}$ See, for example, Jack Knight's (1992) critique of neo-institutional economics along these lines.
} 
others. Reframing these developments as adaptations, however, can help us understand the extent to which certain tragedies of world history — such as European colonialism-were and were not "inevitable."

It was not inevitable, of course, that Columbus be the first European to "discover" the Americas, nor that the Spanish and Portuguese be the first Europeans to begin colonization, nor even that Europeans in general be the first to develop the weapons and other technologies—such as hierarchical state structures - which enabled them to colonize other parts of the world. There is much speculation, for example, about what might have happened if Ming China had not abandoned its proto-colonial exploration in the early $15^{\text {th }}$ century. Nevertheless, there was something inevitable about the spread of hierarchical state structures and advanced weaponry: as long as they really did enable societies to wage war more effectively, someone would eventually have used them for that purpose, causing their spread across the globe through conquest or defensive imitation. In Rosenberg's words, there is a "seething rumble" of strategies being tested "beneath every local equilibrium," and eventually, one of those strategies will break up that equilibrium and precipitate an arms race-in this case, literally.

It is important to note that this in no way diminishes the normative significance of the atrocities committed by particular individuals and Europeans as a group, and it should not prevent us from holding their contemporary descendants accountable for the immense power and privilege they have inherited as a direct result of those atrocities. Even after "adaptive" practices have been discovered, particular individuals, groups, and civilizations can choose not to adopt them. Ming China is sometimes held up as an example of a civilization which made such a choice, and regardless of whether this is an accurate description of that case, the theoretical point stands: people

\footnotetext{
${ }^{17}$ Despite its many flaws, this is one of the valuable shifts in perspective achieved by Jared Diamond's Guns, Germs, and Steel (1997), and the following section draws upon arguments made in that book.
} 
can choose not to adopt harmful practices even if they are "adaptive" in the technical sense elaborated here. But the principle of the "seething rumble" of variation is that someone, eventually, will try it out.

Recognizing that the human practices which proliferate are not those which are truth-tracking or beneficial but those which spread themselves most effectively is certainly a sobering thought. It means, for example, that convincing particular individuals or groups to abandon harmful but adaptive practices will not prevent them altogether - that if we understand the task of moral and political intervention as confined to moral persuasion, in other words, we are dooming it to failure. Rather than recommending despair, however, a Darwinian perspective points the way forward for more effective moral and political intervention in the world. If it is true that, as Rosenberg says, any particular social regularity can be disrupted, then this is also true of the broader ecological circumstances within which particular strategies are locally "inevitable," and this observation clarifies the task of those who seek to prevent the spread of any particular practice. While convincing individuals and groups not to adopt harmful but adaptive practices will not prevent them, that is, such practices can be prevented by identifying the ecological conditions under which they are adaptive, and altering those conditions so that the harmful practices are no longer adaptive. ${ }^{18}$ Convincing many individuals or groups that a practice is evil may be a necessary part of this process, but it is not usually sufficient. Changing our socio-ecological circumstances through coordinated social or political action is also likely to be necessary, and moral and political theorists, in my view, would do well to take this ecological perspective to heart.

\footnotetext{
${ }^{18}$ On this point, see the important work being done in "adversarial ethics," which observes that in competitive contexts such as sports and markets, ethical principles ought not be self-undermining, simply guaranteeing the failure of anyone who follows them (Heath et al., 2010; Norman, 2011). Instead of "opting out" of contexts in which unethical behaviors are profitable, such authors claim, ethical actors in adversarial circumstances should aim to prevent those practices from being profitable in the first place. Ethical norms against unethical practices in competitive contexts, that is, should be thought of as continuous with the social norms and legal regulations which might actually constrain all competitors from engaging in those practices.
} 
These lessons are important. Empirically, we should appreciate the limited character of empirical regularities in social science. Normatively, we must never assume that an "adaptive" or "functional" human practice is beneficial to anyone, much less to society as a whole. Finally, if we want to prevent certain harmful practices from proliferating, we must focus on rendering them maladaptive in general, rather than convincing particular individuals and groups not to adopt them. Important as they are, however, these lessons are at best orthogonal to questions about why people engage in particular cultural practices as opposed to others-the questions, in other words, at the core of socio-historical inquiry. 


\section{References}

Alchian AA (1950) Uncertainty, evolution, and economic theory. The Journal of Political Economy 58(3): 211-221.

Aldrich HE, Hodgson GM, Hull DL, et al. (2008) In defence of generalized Darwinism. Journal of Evolutionary Economics 18(5): 577-596.

Asch SE (1951) Effects of group pressure upon the modification and distortion of judgments. In: Guetzkow H (ed.), Groups, leadership, and men, Pittsburgh: Carnegie Press, pp. 222236.

Bagehot W (1872) Physics and Politics, or, Thoughts on the Application of the Principles of 'Natural Selection' and 'Inheritance' to Political Society. London: Henry King.

Bannister R (1989) Social Darwinism: Science and Myth in Anglo-American Social Thought. Philadelphia: Temple University Press.

Bates RH, Greif A, Levi M, et al. (1998) Analytic Narratives. Princeton: Princeton University Press.

Blackmore S (2000) The meme machine. New York: Oxford University Press.

Bloch M (2012) Anthropology and the Cognitive Challenge. Cambridge: Cambridge University Press.

Blute M (1997) History versus science: The evolutionary solution. Canadian Journal of Sociology/Cahiers canadiens de sociologie: 345-364.

Blute M (2010) Darwinian sociocultural evolution: Solutions to dilemmas in cultural and social theory. Cambridge: Cambridge University Press.

Blute M (2015) Modes of Variation and Their Implications for an Extended Evolutionary Synthesis. In: Machalek R, Maryanski A, and Turner JH (eds), Handbook on evolution and society: toward an evolutionary social science, Boulder, CO: Paradigm Publishers, pp. 59-75.

Boyd R and Richerson PJ (1988) Culture and the evolutionary process. Chicago: University of Chicago Press.

Brandon RN (1990) Adaptation and Environment. Princeton: Princeton University Press.

Bryant JM (2004) An Evolutionary Social Science? A Skeptic's Brief, Theoretical and Substantive. Philosophy of the Social Sciences 34(4): 451-492.

Buenstorf G (2006) How useful is generalized Darwinism as a framework to study competition and industrial evolution? Journal of Evolutionary Economics 16(5): 511-527. 
Campbell D (1965) Variation, Selection and Retention in Sociocultural Evolution. In: Barringer HR, Blankstein GI, and Mack RW (eds), Social Change in Developing Areas: A Reinterpretation of Evolutionary Theory, Cambridge, MA: Schenkman, pp. 19-49.

Chase-Dunn C (2015) The Sociocultural Evolution of World-systems. In: Machalek R, Maryanski A, and Turner JH (eds), Handbook on evolution and society: toward an evolutionary social science, Boulder, CO: Paradigm Publishers, pp. 267-284.

Christiansen MH and Richerson PJ (2013) Cultural evolution : society, technology, language, and religion. Cambridge: MIT Press.

Cordes C (2006) Darwinism in economics: from analogy to continuity. Journal of Evolutionary Economics 16(5): 529-541.

Darwin C (1859) On the Origin of Species. London: John Murray.

Dawkins R (1976) The Selfish Gene. New York: Oxford University Press.

Degler CN (1991) In Search of Human Nature: The Decline and Revival of Darwinism in American Social Thought. New York: Oxford University Press.

Dennett D (1996) Darwin's Dangerous Idea: Evolution and the Meanings of Life. New York: Simon and Schuster.

Diamond JM (1997) Guns, Germs, and Steel. New York: Norton.

Foster J (1997) The analytical foundations of evolutionary economics: From biological analogy to economic self-organization. Structural Change and Economic Dynamics 8(4): 427451.

Geertz C (1973) The interpretation of cultures: Selected essays. New York: Basic Books.

George AL and Bennett A (2005) Case Studies and Theory Development in the Social Sciences. Cambridge: MIT Press.

Godfrey-Smith P (1999) Adaptationism and the Power of Selection. Biology and Philosophy 14(2): 181-194.

Godfrey-Smith P (2001) Three kinds of adaptationism. In: Orzack SH and Sober E (eds), Adaptationism and optimality, pp. 335-357.

Gould SJ and Lewontin RC (1979) The spandrels of San Marco and the Panglossian paradigm: a critique of the adaptationist programme. Proceedings of the Royal Society of London B: Biological Sciences 205(1161): 581-598.

Hallpike CR (1986) The principles of social evolution. Oxford: Clarendon Press.

Hannan MT and Freeman J (1977) The population ecology of organizations. American journal of sociology: 929-964. 
Hayek FA (1973) Law, Legislation and Liberty, Volume 1: Rules and Order. Chicago: University of Chicago Press.

Heath J, Moriarty J and Norman W (2010) Business Ethics and (or as) Political Philosophy. Business Ethics Quarterly 20(3): 427-452.

Hodgson GM (2004) Social Darwinism in Anglophone Academic Journals: A Contribution to the History of the Term. Journal of Historical Sociology 17(4): 428-463.

Hodgson GM and Knudsen T (2010) Darwin's conjecture: The search for general principles of social and economic evolution. Chicago: University of Chicago Press.

Hofstadter R (1944) Social Darwinism in American Thought, 1860-1915. Philadelphia: University of Pennsylvania Press.

Ingold T (2007) The Trouble with 'Evolutionary Biology'. Anthropology Today 23(2): 13-17.

Knight J (1992) Institutions and social conflict. Cambridge: Cambridge University Press.

Kronfeldner ME (2006) Is cultural evolution Lamarckian? Biology \& Philosophy 22(4): 493512.

Kuran T (1989) Sparks and prairie fires: A theory of unanticipated political revolution. Public Choice 61(1): 41-74.

Kuran T and Sunstein C (1999) Availability cascades and risk regulation. Stanford Law Review 51(4).

Laland KN and Brown GR (2002) Sense and nonsense: Evolutionary perspectives on human behaviour. New York: Oxford University Press.

Lewens T (2002) Darwinnovation! Studies in History and Philosophy of Science 33(1): 199-207.

Lewens T (2008) Seven types of adaptationism. Biology \& Philosophy 24(2): 161-182.

Lewens T (2015) Cultural Evolution: Conceptual Challenges. Oxford: Oxford University Press.

Mace R and Jordan FM (2011) Macro-evolutionary studies of cultural diversity: a review of empirical studies of cultural transmission and cultural adaptation. Philosophical Transactions of the Royal Society of London B: Biological Sciences 366(1563): 402-411.

Mesoudi A (2007) Foresight in cultural evolution. Biology \& Philosophy 23(2): 243-255.

Mesoudi A (2010) Evolutionary Synthesis in the Social Sciences and Humanities. Cultural Science Journal 3(1).

Mesoudi A (2011) Cultural evolution: how Darwinian theory can explain human culture and synthesize the social sciences. Chicago: University of Chicago Press. 
Mesoudi A, Whiten A, Laland KN, et al. (2006) Towards a unified science of cultural evolution. Behavioral and Brain Sciences 29(4): 329-346.

Mills SK and Beatty JH (1979) The Propensity Interpretation of Fitness. Philosophy of Science 46(2): 263-286.

Morgan LH (1877) Ancient Society: Or, Researches in the Lines of Human Progress from Savagery, Through Barbarism to Civilization. London: Macmillan.

Nelson RR and Winter S (1982) An Evolutionary Theory of Economic Change. Cambridge: Belknap Press.

Norman W (2011) Business ethics as self-regulation: Why principles that ground regulations should be used to ground beyond-compliance norms as well. Journal of business ethics 102(1): 43-57.

Richerson PJ and Boyd R (2008) Not by genes alone: How culture transformed human evolution. Chicago: University of Chicago Press.

Rosenberg A (1983) Fitness. The Journal of Philosophy 80(8): 457-473.

Rosenberg A (2015) The Biological Character of Social Theory. In: Machalek R, Maryanski A, and Turner JH (eds), Handbook on evolution and society : toward an evolutionary social science, Boulder, CO: Paradigm Publishers, pp. 31-58.

Runciman WG (2009) The theory of cultural and social selection. Cambridge: Cambridge University Press.

Sanderson SK (2001) The Evolution of Human Sociality: A Darwinian Conflict Perspective. New York: Rowman \& Littlefield.

Sanderson SK (2015) Darwinian Conflict Theory: A Unified Evolutionary Research Program. In: Machalek R, Maryanski A, and Turner JH (eds), Handbook on evolution and society: toward an evolutionary social science, Boulder, CO: Paradigm Publishers, pp. 228-264.

Schubert C (2014) 'Generalized Darwinism' and the quest for an evolutionary theory of policymaking. Journal of Evolutionary Economics 24(3): 479-513.

Smart JJC (1959) Can biology be an exact science? Synthese 11(4): 359-368.

Spencer H (1895) The principles of sociology. New York: Appleton and Co.

Sperber D (2000) An Objection to the Memetic Approach to Culture. In: Aunger R (ed.), Darwinizing Culture: The Status of Memetics as a Science, Oxford: Oxford University Press, pp. 163-173. 
Sterrett SG (2002) Darwin's analogy between artificial and natural selection: how does it go? Studies in History and Philosophy of Science Part C: Studies in History and Philosophy of Biological and Biomedical Sciences 33(1): 151-168.

Turner JH and Maryanski A (2015) The Prospects and Limitations of Evolutionary Theorizing in the Social Sciences. In: Machalek R, Maryanski A, and Turner JH (eds), Handbook on evolution and society : toward an evolutionary social science, Boulder, CO: Paradigm Publishers, pp. 92-111.

Tylor EB (1873) Primitive culture: researches into the development of mythology, philosophy, religion, art, and custom. London: John Murray.

Veblen T (1899) The theory of the leisure class; an economic study of institutions. London: Macmillan.

Wilson EO (1975) Sociobiology. The New Synthesis. Cambridge: Harvard University Press.

Winter S (1964) Economic 'Natural Selection' and the Theory of the Firm. Yale Economic Essays 4(1): 225-272.

Witt U (2004) On the proper interpretation of 'evolution' in economics and its implications for production theory. Journal of Economic Methodology 11(2): 125-146. 